\title{
TENS IN MID CLAVICULAR FRACTURES
}

\author{
Aman Bansal ${ }^{1}$, Surinder Singh Ajrawat², Ajaybir Singh ${ }^{3}$, Shiveta Bansal ${ }^{4}$ \\ ${ }^{1}$ Associate Professor, Department of Orthopaedics, Punjab Institute of Medical Sciences. \\ ${ }^{2}$ Assistant Professor, Department of Orthopaedics, Punjab Institute of Medical Sciences. \\ 3Senior Resident, Department of Orthopaedics, Punjab Institute of Medical Sciences. \\ ${ }_{4}^{4}$ Associate Professor, Department of Physiology, Punjab Institute of Medical Sciences.
}

\begin{abstract}
BACKGROUND

The midshaft clavicle fractures account for 3 to $5 \%$ of all injuries and 70 to $80 \%$ of all clavicle fractures in young adults; these fractures are usually related to sports or vehicle accidents, whereas in children and elderly they are usually related to falls. In general, clavicle fractures are treated conservatively and have a good outcome. In 1960, Neer reported a non-union rate of $0.1 \%$ with conservative treatment and Rowe corroborated these findings in 1968 and showed a non-union rate of $0.8 \%$ in conservatively managed patients. Since then, however, other authors have failed to demonstrate similar good results with conservative treatment. More recently, there has been a trend toward surgical fixation. Surgery has been indicated for completely displaced fractures, potential skin perforation, shortening of clavicle by more than $20 \mathrm{~mm}$, neurovascular injury and floating injury. The gold standard for the surgical treatment has been open reduction and plate fixation through a large incision. Other surgical options include intramedullary pinning with Kirschner wire, Rush pins, Knolwes pin, Steinman pin, Haige pin, ESIN (Elastic Stable Intramedullary Nailing) and external fixation.
\end{abstract}

\section{MATERIALS AND METHODS}

We analysed the consecutive series of 38 patients who presented to us with clavicle fractures between January 2013 to June 2015 and they were treated with TENS. All the patients were reviewed postoperatively in the clinic at 2, 6, 12 weeks and 6 months or until the fracture had healed clinically and radiologically. The aim of the present study was to evaluate the functional and radiological results of intramedullary fixation of mid-clavicular fractures.

\section{RESULTS}

All the patients achieved clinical and radiological union at a mean of 11.3 weeks (Range, 6-20 weeks). Eleven of the 38 patients had closed nailing while 27 patients $(71 \%)$ required open reduction of their fracture. There was no statistical difference between the functional scores and the range of movement when the scores were compared at 3, 6 months and the last follow-up. The average Oxford Shoulder Score was 45.6 (range, 37-48). The average Quick DASH score was 6.7 (Range, 0-13.6) at the last follow-up.

\section{CONCLUSION}

Titanium elastic nails are a promising minimally invasive treatment for displaced mid-clavicular fractures, which may be an alternative to plate fixation (ORIF) or even non-operative treatment.

\section{KEYWORDS}

Tens, Mid Clavicular Fractures, Clavicle, Nailing

HOW TO CITE THIS ARTICLE: Bansal A, Ajrawat SS, Singh A, et al. Tens in mid clavicular fractures. J. Evolution Med. Dent. Sci. 2016;5(77):5725-5727, DOI: 10.14260/jemds/2016/1291

\section{INTRODUCTION}

The midshaft clavicle fractures account for 3 to $5 \%$ of all injuries and 70 to $80 \%$ of all clavicle fractures.[1,2] In young adults, these fractures are usually related to sports or vehicle accidents, whereas in children and elderly they are usually related to falls.[1,2] In general, clavicle fractures are treated conservatively and have a good outcome. In 1960, Neer reported a non-union rate of $0.1 \%$ with conservative treatment ${ }^{3]}$ and Rowe corroborated these findings in 1968 and showed a non-union rate of $0.8 \%$ in conservatively

Financial or Other, Competing Interest: None.

Submission 11-09-2015, Peer Review 12-09-2015,

Acceptance 09-04-2016, Published 24-09-2016.

Corresponding Author:

Dr. Aman Bansal,

Associate Professor

Department of Orthopaedics,

Punjab Institute of Medical Sciences, Jalandhar.

E-mail:dramanbansal@gmail.com

DOI: $10.14260 /$ jemds $/ 2016 / 1291$ managed patients. ${ }^{[4]}$ Since then, however, other authors have failed to demonstrate similar good results with conservative treatment. [5,6] This may be due to the fact that the initial series included children and adolescents and their enormous potential for bone healing may have skewed the results, and that patient-based scoring systems were not used in the initial series to record the outcome.[7] Hill et al showed that displacement of more than $20 \mathrm{~mm}$ resulted in $15 \%$ non-union and $18 \%$ of the patients had thoracic outlet syndrome following union.[5] McKee et al noted reduced patient satisfaction due to asymmetry and cosmesis following malunion in patients with more than $20 \mathrm{~mm}$ shortening.[6] Hence, more recently, there has been a trend toward surgical fixation. Surgery has been indicated for completely displaced fractures, potential skin perforation, shortening of clavicle by more than $20 \mathrm{~mm}$, neurovascular injury and floating injury. ${ }^{[8]}$ The gold standard for the surgical treatment has been open reduction and plate fixation through a large incision. ${ }^{[8]}$ Other surgical options include intramedullary pinning with Kirschner wire, Rush pins, Knolwes pin, Steinman pin, Haige 
pin, ESIN (Elastic Stable Intramedullary Nailing) and external fixation. ${ }^{[9]}$

The aim of the present study was to evaluate the functional and radiological results of intramedullary fixation of midclavicular fractures.

\section{MATERIALS AND METHODS}

We analysed the consecutive series of 38 patients who presented to us with clavicle fractures between January 2013 to June 2015 and they were treated with TENS.

The inclusion criteria for this study were diaphyseal midshaft, non-comminuted clavicle fractures with more than $20 \mathrm{~mm}$ shortening/displacement in any view. Exclusion criteria were patients with proximal or distal fractures, floating shoulder, brachial plexus injury and comminuted fractures.

There were 32 males and six females in this study. The mean age was 27.6 years (Range, 14 to 57 years).

All the patients were reviewed postoperatively in the clinic at 2, 6, 12 weeks and 6 months or until the fracture had healed clinically and radiologically.

All the patients were assessed for clinical and radiological union and radiographs were taken at each clinic visit. We defined radiological union as visible bridging callus or absent fracture line. The clinical union was described as no bony tenderness on clinical examination. All the patients had Oxford Shoulder score and Quick DASH score, which were done at the time of their final follow-up. The Oxford Shoulder score, which is a questionnaire-based subjective assessment of the patients' pain and impairment of activities of daily living, has shown to correlate well with the Constant Score and SF 36 assessment.[10] The Quick DASH is a shortened version of the DASH outcome score and uses 11 items instead of the 30 items in the full questionnaire to measure physical function and symptoms in patients with any or multiple musculoskeletal disorders of the upper limb.[11]

\section{Surgical Technique}

After administration of anaesthesia, the patient was placed in beach chair position with injured extremity prepared and draped from the midline to the upper arm. Care was taken to make sure that the sternoclavicular joint was accessible for the entry point. Preoperatively, the shoulder region was screened using image intensifier to confirm this access.

A vertical skin incision was made just lateral to the sternoclavicular joint. The subcutaneous fat was incised along with platysma. The pectoral fascia was divided in line with the skin incision followed by careful elevation of the underlying musculature from the clavicle. The entry point was then made using the awl and appropriate sized titanium ESIN was inserted.

Attempt was made to close reduce the fracture. If the fracture could not be reduced by closed means, then a separate vertical incision was used at the fracture site to aid fracture reduction. Vertical incision was used as it was parallel to Langer's lines and minimised the risk of damage to supraclavicular nerves to avoid dysaesthesia of skin and scar neuromas. At that time, the nail was used to create a path in the lateral end of the clavicle for subsequent easy access. The nail was then passed from the medial side and across the reduced fracture into the lateral end of clavicle. All the patients were put in a shoulder sling postoperatively and followed same rehabilitation regime of early gentle mobilisation when pain allows with no overhead abduction for first six weeks. The shoulder sling was discarded at 2 weeks and activeassisted exercises were started, but the patients were advised not to lift any heavy object for 6 weeks. At that time, passive and strengthening exercises were started.

\section{RESULTS}

A total of 38 patients met the inclusion criteria of diaphyseal midshaft, non-comminuted clavicle fractures with more than $20 \mathrm{~mm}$ shortening/displacement. Of these 38 patients 22 patients had a fall on outstretched hand, 7 had a fall from bicycle, 2 had a fall from height, 3 had a fall onto the point of shoulder, and 4 had road traffic accident. The average followup was 12 months (Range, 6-24 weeks).

All the patients achieved clinical and radiological union at a mean of 11.3 weeks (Range, 6-20 weeks). Eleven of the 38 patients had closed nailing, while 27 patients $(71 \%)$ required open reduction of their fracture. The average size of the titanium flexible nail used was $2 \mathrm{~mm}$ (Range, $1.5-3 \mathrm{~mm}$ ).

The patients were followed up postoperatively and Oxford Shoulder score and QuickDASH scores were calculated 6 weeks, 3 months, 6 months and at the last follow-up. There was no statistical difference between the functional scores and the range of movement when the scores were compared at 3 , 6 months and the last follow-up.

The average Oxford Shoulder score was 45.6 (Range, 37 48). The average QuickDASH score was 6.7 (Range, 0-13.6) at the last follow-up.

Eighteen of 38 patients had removal of the implant for symptomatic medial irritation, 7-9 months after the initial operation and after their fracture had clinically and radiologically healed. One patient required trimming of medial end of nail and one patient had lateral protrusion of the nail which was subsequently removed.

There were no major complications in our series with no cases of infections, scar neuromas, non-unions or perforation of the posterior cortex.

\section{DISCUSSION}

Plate osteosynthesis is still considered the standard method for the surgical treatment of clavicle shaft fractures. The advantage of this technique is good reduction with compression and rigid fixation. However, complications after plate osteosynthesis are fairly common. In a multicenter prospective randomised trial, plate osteosynthesis had better functional outcome than non-operative treatment of displaced clavicle fractures with decreased rate of non-union and symptomatic malunion.[12]

Intramedullary stabilisation is an established alternative fixation method. Intramedullary implants are optimal from biomechanical point of view as the tension side of clavicle changes with respect to rotation of arm and direction of loading. ${ }^{[7,13]}$ The potential benefits of this technique include smaller incision, minimal periosteal stripping and load sharing device properties.[12] Its relative stability allows copious callus formation during the healing process. The frequent complication includes skin irritation from the prominent medial end of the nail and this frequently leads to either trimming of the nail or its premature removal.[13]

Multifragmentary fracture can lead to telescoping of the nail with shortening of the clavicle. The comminuted fractures 
were excluded, because we believe that this fixation system cannot maintain length of the clavicle in these situations. Smekal et al hence do not recommend use of ESIN in comminuted fractures with severe shortening. [13] Duan et al in a meta-analysis of randomised controlled trials demonstrated similar functional outcome when comparing plating with intramedullary fixation.[1] They, however, showed higher symptomatic hardware-related problems with plating.[1] Zolowodzki et al in a systematic review of 2144 cases found non-union rate of $1.6 \%$ with intramedullary fixation as compared with $2.5 \%$ with plate fixation. ${ }^{[11]}$

Smekal et al showed in a randomised control trial between intramedullary nailing and non-operative treatment, better DASH and Constant scores and $100 \%$ union rate with intramedullary nailing.[7] Liu et al found no significant difference between functional outcome and non-union rate following plate fixation and intramedullary fixation (titanium elastic nails) of displaced midshaft clavicle fractures.[14]

Frigg et al in their study expressed concerns about the increased complication rate. ${ }^{[8]}$ In one of our patients, the nail was left slightly proud and required trimming later on. The other patient with lateral protrusion (Without any involvement of the acromioclavicular joint) had minimal discomfort from it and this nail was removed once the fracture had healed. Migration of intramedullary implant has been reported in a number of studies.

Smekal et al reported that $23 \%$ of their patients had medial nail protrusion and $89 \%$ of the patients required implant removal.[7] $47 \%$ of our patients had the implant removed, most of them for symptomatic medial irritation. Smekal et al reported rate of closed vs open fracture reduction when using elastic flexible intramedullary nailing of 64:36.[7] In our study, 27 cases of $38(71 \%)$ required open reduction, which was done through a small vertical incision at the fracture site with a minimally invasive approach. We do not consider open reduction of the fracture as unsatisfactory; despite its high rate in our series we achieved $100 \%$ union.

\section{CONCLUSION}

The acute treatment of middle-third clavicle fractures remain a subject of controversy. In comparison with plate fixation, TENS is less invasive and requires smaller incisions. In comminuted fractures that are at risk of telescoping, plate fixation however remains the procedure of choice. The data demonstrates early pain relief in combination with good shoulder function after acute operative treatment resulting in quick return to sports activities and a high patient satisfaction rate. Titanium elastic nails are a promising minimally invasive treatment for displaced mid-clavicular fractures, which may be an alternative to plate fixation (ORIF) or even nonoperative treatment.

\section{REFERENCES}

1. Duan X, Zhong G, Cen S, et al. Plating versus intramedullary pin or conservative treatment for midshaft fracture of clavicle: a meta-analysis of randomized controlled trials. J Shoulder Elbow Surg 2011;20(6):1008-15.

2. Schiffer G, Faymonville C, Skouras E, et al. Midclavicular fracture: not just a trivial injury: current treatment options. Dtsch Arztebl Int 2010;107(41):711-7.

3. Neer CS. Nonunion of the clavicle. J Am Med Assoc 1960; 172:1006-11.

4. Rowe CR. An atlas of anatomy and treatment of midclavicular fractures. Clin Orthop Relat Res 1968; 58:29-42.

5. Hill JM, McGuire MH, Crosby LA. Closed treatment of displaced middle-third fractures of the clavicle gives poor results. J Bone Joint Surg Br 1997;79(4):537-9.

6. McKee MD, Pedersen EM, Jones C, et al. Deficits following nonoperative treatment of displaced midshaft clavicular fractures. J Bone Joint Surg Am 2006;88(1):35-40.

7. Smekal V, Irenberger A, Struve $\mathrm{P}$, et al. Elastic stable intramedullary nailing versus nonoperative treatment of displaced midshaft clavicular fractures-a randomized, controlled, clinical trial. J Orthop Trauma 2009;23 (2):106-12.

8. Frigg A, Rillmann P, Perren T, et al. Intramedullary nailing of clavicular midshaft fractures with the titanium elastic nail: problems and complications. Am J Sports Med 2009;37(2):352-9.

9. Khalil A. Intramedullary screw fixation for midshaft fractures of the clavicle. Int Orthop 2009;33(5):1421-4.

10. Dawson J, Hill G, Fitzpatrick R, et al. The benefits of using patient-based methods of assessment. Medium-term results of an observational study of shoulder surgery. J Bone Joint Surg Br 2001;83(6):877-82.

11. Beaton DE, Wright JG, Katz JN, et al. Development of the quickdash: comparison of three item reduction approaches. J Bone Joint Surg Am 2005;87(5):1038-46.

12. Canadian orthopaedic trauma society. Nonoperative treatment compared with plate fixation of displaced midshaft clavicular fractures. A multicentre clinical randomized trial. J Bone Joint Surg Am 2007;89(1):1-10.

13. Smekal V, Irenberger A, Attal RE, et al. Elastic stable intramedullary nailing is best for mid-shaft clavicular fractures without comminution: results in 60 patients. Injury 2011;42(4):324-9.

14. Liu HH, Chang $\mathrm{CH}$, Chia WT, et al. Comparison of plates versus intramedullary nails for fixation of displaced midshaft clavicular fractures. J Trauma 2010;69(6): E82-7. 